\title{
NEMO educational kit on micro- optics at the secondary school
}

\section{Flores-Arias, Carmen Bao-Varela}

M. T. Flores-Arias, Carmen Bao-Varela, "NEMO educational kit on microoptics at the secondary school," Proc. SPIE 9289, 12th Education and Training in Optics and Photonics Conference, 928911 (17 July 2014); doi: $10.1117 / 12.2070758$

SPIE Event: 12th Education and Training in Optics and Photonics Conference, 2013, Porto, Portugal 


\title{
NEMO Educational Kit on Micro-Optics at the Secondary School
}

\author{
M.T.Flores-Arias* ${ }^{*}$ and C. Bao-Varela \\ Grupo de Microóptica y Óptica GRIN, Facultade de Física y Facultade de Óptica y Optometría, \\ Universidade de Santiago de Compostela, Campus Vida s/n 15782, Santiago de Compostela, Spain
}

\begin{abstract}
NEMO was the "Network of Excellence in Micro-Optics" granted in the "Sixth Framework Program" of the European Union. It aimed at providing Europe with a complete Micro-Optics food-chain, by setting up centers for optical modeling and design; measurement and instrumentation; mastering, prototyping and replication; integration and packaging and reliability and standardization. More than 300 researchers from 30 groups in 12 countries participated in the project. One of the objectives of NEMO was to spread excellence and disseminate knowledge on micro-optics and micro-photonics. To convince pupils, already from secondary school level on, about the crucial role of light and micro-optics and the opportunities this combination holds, several partners of NEMO had collaborate to create this Educational Kit. In Spain the partner involved in this aim was the "Microoptics and GRIN Optics Group" at the University of Santiago of Compostela (USC).
\end{abstract}

The educational kits provided to the Secondary School were composed by two plastic cards with the following microoptical element: different kinds of diffractive optical elements or DOES and refractive optical elements or ROEs namely arrays of micro-lenses. The kit also included a DVD with a handbook for performing the experiments as well as a laser pointer source.

This kit was distributed free of charge in the countries with partners in NEMO. In particular in Spain was offered to around 200 Secondary School Centers and only 80 answered accepting evaluate the kit.

Keywords: secondary school, active learning, optics education

\section{INTRODUCTION}

According to the Lund Declaration of July 2009, European research must focus on the 'grand challenges' of our time. Photonics was declared as a key enabling technology to tackle such challenges as healthcare in an ageing society, energy efficiency and climate change, the knowledge society, the digital divide and public safety and security. Nevertheless, a shortage of well-qualified employees in photonics was identified as a problem to address in the coming years. The solution would be to establish concerted actions at all levels of education from primary level through to postgraduate level to promote photonics. One of these actions would be the distribution of educational material and educational kits to schools, this will stimulate broader interest in photonics and will allow increasing the number of photonics students. New technologies are becoming indispensable in all education levels and the development of educational kits for promoting active learning is one of the more remarkable aims. Integrating university teachers in conjunction with secondary teacher in conventional classroom practices can be a very useful way to improve student's skills. Primary and secondary education, typically up to age 18 or 19, focus on basic skills. Most national curricula include some elementary optics and photonics but as a ruele the widespread uses and applications of photonics are not presented to students.

*maite.flores@usc.es; carmen.bao@usc.es; phone: +34881813502; fax: +34881813642

12th Education and Training in Optics and Photonics Conference, edited by

Manuel F. P. C. Martins Costa, Mourad Zghal, Proc. of SPIE Vol. 9289, 928911

(c) 2014 SPIE, OSA, IEEE, ICO · doi: 10.1117/12.2070758

Proc. of SPIE Vol. $9289928911-1$ 
Tacking into account the important role of photonics in the European Research Area for coming years ${ }^{1}$, it would be recommended to increase the number of lessons and teachers specialist on photonics, in order to motivate the pupils at the secondary school in these disciplines. In this regard, several resources have been developed for teaching optics and photonics, in particular the Network of Excellence on Microoptics (NEMO) granted in the Sixth Framework Program of the European Union, developed a workpackage devoted to the spreading excellence and disseminate knowledge on micro-optics and micro-photonics.

The aims of NEMO were providing Europe with a complete Micro-Optics food-chain, by setting up centers for optical modeling and design; measurement and instrumentation; mastering, prototyping and replication; integration and packaging and reliability and standardization. More than 300 researchers from 30 groups in 12 countries were involved in the project.

To convince pupils, already from secondary school level, about the crucial role of light and micro-optics and the opportunities this combination holds, several partners of NEMO have collaborated to create this Educational Kit.

The kit was supplemented with an educational booklet with DVD, which explains the use of the components at different level: low-level explanations for secondary schools, and more sophisticated explanations for high schools or universities. Possible experiments and experimental setups were proposed, explained and illustrated. On the same DVD some simple optical designs were also illustrated ${ }^{2}$.

The EduKit was disseminated through student chapters in Argentina, Belgium, Canada, China, Colombia, India, Latvia, Mexico, Peru, Russia, Singapore, South Africa, and the United States ${ }^{3}$ and, in Spain by our researching group.

The aim of this work is to analyze the impact of the Edukit distribution in Spain, the problems encountered in the distribution as well as the evaluation obtained from the participants.

\section{DESCRIPTION OF THE EDUKIT CONTAINTS}

The Edukit was provided with a educational booklet with DVD, a laser source and two small plastic card, where you can find different kinds of diffractive optical elements or DOEs, and also refractive optical elements or ROEs namely arrays of micro-lenses ${ }^{4}$.

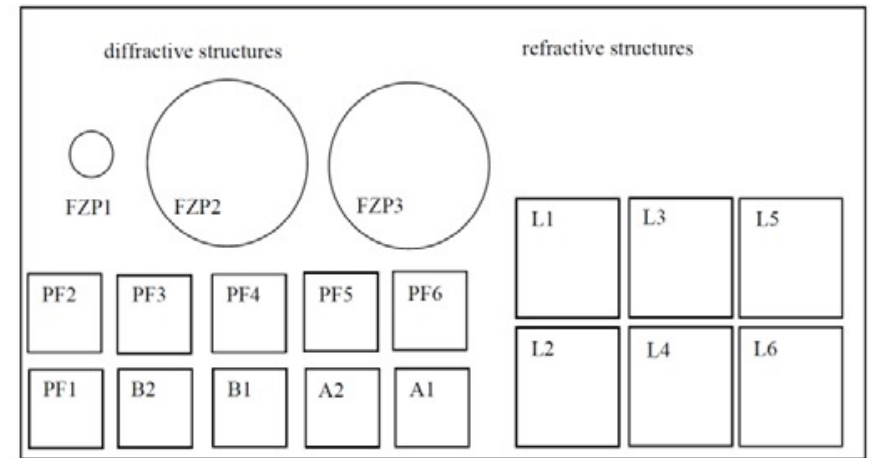

Figure 1. Distribution of the different microoptic elements on the plastic card
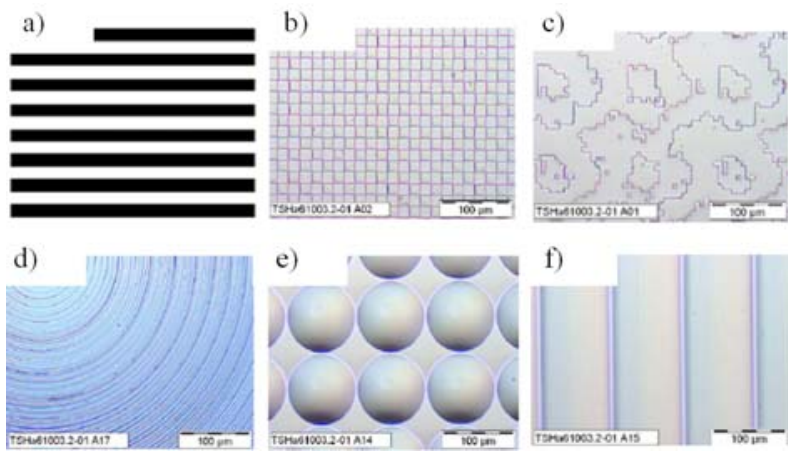

f)

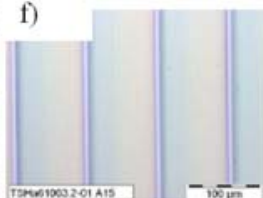

Figure 2. a) linear and b)crossed gratings, c) DOE, d) Fresnel Zone Plate, e)spherical and f)cylindrical microlenses. 
Figure 1 show the microoptic elements distribution on each one of the plastic cards supplied. Elements number A1 and A2 are simple linear gratings, with different pitch. B1 and B2 are crossed grating with decreasing spatial frequency. PF1 and PF2 are array generators or "fan-out" elements; PF3 is a flattop generator; PF4 gives a square grid; PF5 shows the logo of the NEMO network and PF6 produces a European flag. On the card there also are three Fresnel Zone Plates (FZP), with different focal lengths. Elements L1 till L6 are arrays of microlenses. The topography of some of them is shown in figure 2.

The laser source supplied emits at a wavelength of $635 \mathrm{~nm}$, for which the microelements were designed, and has less than $1 \mathrm{~mW}$ power (safety class 2). In Europe, safety standards are given in the European Norm EN-60 825-1. In that norm, lasers are classified in different "laser-safety classes", depending on their power and emitted wavelength.

\section{EDUKIT DISTRIBUTION IN SPAIN}

The programs of Science (and in particular Physics) along the primary and secondary studies in Spain usually cover a small number of topics in Optics. In general, Mechanics and Electromagnetism are much better covered during these studies. Usually, some Optics contents are introduced in the two last years of the secondary school. Nevertheless, due to time restrictions, only general concepts about Waves, and also Geometrical Optics are treated. So, it is not strange that the relation between Optics and advanced Technology is unknown to the students, and as a consequence, few of them are motivated to study Optics in the future ${ }^{5}$. The main goal of our research group was to convince pupils and teacher from the secondary school about the importance that Photonics in general, and Microoptics in particular, plays in daily life in the European society. The edukit distribution was implemented in two stages. Because of the big geographic area of Spain, the first stage was carried out only in the Galician region where the University of Santiago de Compostela (USC) is located. In this stage, people involved in this task moved to the Secondary School for helping the teacher to implement different experiences that can be done with the edukit. They also explained to pupils and teachers, that microoptics is a collective term for very small optical structures and components (around the magnitude of the thickness of a human hair) which enable the manipulation, collection and distribution of light. These are used in many products encounters in daily life: in displays (mobile phones, GPS modules, digital camera's...); for sensing applications (in card distance control, in windshield wiper activators, in structural health monitoring systems, in food quality control, in barcode readers, in novel surgical and medical instruments...) for computing and data storage (CD-and DVD-players, Optical data communications...). Due to the interest awakened in these schools, we decided carry out the second stage of the project, expanding distribution throughout Spain. First, we identified the secondary and bachelor centers with technological branch in their curricula. This information is available in database of the Spanish Education Ministry. In order to distribute the kits proportionally by regional government, we chose some centers from each part of Spain. To those centers, we sent a letter explaining the aim of the edukit, completely free of charges, and asking for their interest in it. Around 200 centers were contacted and we received only 80 affirmative responses. We asked only returning an evaluation report. In this second stage, due to large distance in Spain (504.782 km², including Balearic and Canary Islands), none of us visited the centers for helping the teacher in the practical tutorials.

In most cases, it was the teachers who evaluated the edukit, since they could not carry out the experiment due to the time limitation of the academic courses or because it was about to finish the academic course. Nevertheless, the centers that had time enough for performing the proposed experiences, evaluated very positively the edukit.

Some remarks about the kit were that the level of some of the proposed experiences was too high for secondary school and even for high school, for the defined Spanish curricula. In particular, they found problems for explaining the basis knowledge to a good understanding of the diffraction optical elements included in the plastic cards. All of them highly appreciated the handbook included in the DVD, even for their own knowledge.

Other teachers commented their difficulties for implementing the experiences because of the lack, in their institutions, of opto-mechanical component.

Comparing the evaluations received from teacher outside of the Galician region with those from Galicia, where some of us assist them for implementing the setup, we realize that a training period for teachers as well as online assistance, will improve the results of these experiments.

On the other hand, the students attending to the practical lesson with this edukit, showed a great interest in the explanations and actively participated in the discussion of the obtained results. In their opinion, the use of this kit will allow them to discover a new point of view of the science and technology, in particular of the optics and photonics. 


\section{CONCLUSIONS}

The NEMO edukit for spreading and dissemination of knowledge on Photonics, in particular on Microoptics was distributed throughout Spain. It was evaluated by several Spanish secondary and high school teachers and students, chosen among all the center with technological branch in their curricula by the researcher of the "Microoptics and Optics GRIN group", of the USC, partner of NEMO. Both of them, students and teachers evaluated positively the kit, although the teachers considered the kit as high level for the Spanish designed curricula. They also argued difficulties for performing the setups, due to lack of opto-mechanical materials in their laboratories. In our experience, these edukits may be more effective if teachers with high expertise in photonics act as trainers for secondary and high school teachers.

\section{REFERENCES}

[1] Second Strategic Research Agenda in Photonics: Lighting the wave ahead. Photonics21, Second Edition, January 2010.

[2] Taghizadeh, M. R., Stijns, Erik, and Hugo Thienpont, “The NEMO educational kit”, Proceedings, Ninth International Topical Meeting on Education and Training in Optics and Photonics (ETOP), Marseille, France

[3] Fabian D., Vermeulen N. and van Overmeire S. , "Student Chapters: effective dissemination networks for informal optics and photonics education” Proceedings, Eleventh International Topical Meeting on Education and Training in Optics and Photonics (ETOP), United Kingdom.

[4] DVD Learn and Teach Optics: NEMO's Educational KIT on Micro-Optics. Supported by the European Commission.

[5] Escalera J. C., Abelló C., Ferreras O., Matheu P., Torres M. and Yzuel M. J., “Guided Poster Sessions: a way to introduce Optical Technology in a primary-secondary school” Proceedings, Eleventh International Topical Meeting on Education and Training in Optics and Photonics (ETOP), United Kingdom. 